\title{
Deconstructing hierarchies: Service users as co-teachers in occupational therapy education
}

\author{
Shira Yalon-Chamovitz ${ }^{\mathrm{a}, *}$, Yoav Kraiem ${ }^{\mathrm{a}}$ and Carolyn Gutman ${ }^{\mathrm{b}}$ \\ ${ }^{a}$ Department of Occupational Therapy, Ono Academic College, Kiryat Ono, Israel \\ ${ }^{\mathrm{b}}$ Department of Social Work, Tel Hai College, Upper Galilee, Israel
}

Received 24 January 2016

Accepted 18 July 2016

\begin{abstract}
.
BACKGROUND: While occupational therapy currently tends to view itself as operating based on a client-centered, collaborative approach, studies often reflect a gap between rhetoric and practice.

OBJECTIVE: This work presents a new pedagogic standard which moves away from the medical model and toward a collaborative, client-centred approach. It functions to support a practice which embraces the respect for, and partnership with, people receiving services and replaces historic patterns which may strengthen the legitimacy of the professional and sustain clients' dependence.

METHODS: This pedagogy develops a therapeutic dialogue which draws from partnerships created in the classroom, where occupational therapy students engage in courses with a co-teacher service user, and examines how the collaboration with service users contributes to the training of occupational therapy students.

CONCLUSIONS: Students and co-teachers can participate in the challenging experience of integrating theoretical knowledge with lived experience, thereby augmenting the development of a new and inclusive knowledge base.
\end{abstract}

Keywords: Co-teaching, service users, social model of disability, critical pedagogy, disability studies

\section{Introduction}

This article explores the development of an educational framework for health and welfare professionals, as well as its role in the enhancement of the pedagogical knowledge base. We describe a pedagogical model incorporating service users (otherwise referred to as clients, patients etc.) as co-teachers that was developed through an interdisciplinary collaboration between an occupational therapy educator, a social work educator, and a service user with disabilities. Here, we present the preliminary model as well as the specific experience of a series of occupational therapy classes co-led by a faculty member and a service user in an occupational therapy program.

*Address for correspondence: Shira Yalon-Chamovitz, Ph.D, OTR, Department of Occupational Therapy, Ono Academic College, Kiryat Ono, 55000, Israel. Tel.: +97235311791; Fax: +97235311888; E-mail: shirayc@ono.ac.il.

\section{Brief review: Occupational therapy and disability}

Although historically occupational therapy's view of disability reflects a holistic approach based on humanism and moral treatment $[1,2]$, the 1950s and early 1960s ushered in a paradigm strongly rooted in the medical model. This perspective replaced the historical view of impairment or disability as stemming from the person-environment relationship with an emphasis on physiological impairment as located within the person [3]. Following this, major occupational therapy leaders called for a return to the holistic, humanistic foundation of the profession $[4,5]$, which translated into the development of client-centered approaches as best practice, and reclaimed the biopsychosocial model as the basis for occupational therapy practice [1]. While presently, occupational therapy tends to see itself as operating 
based on a client-centered approach which reflects the notion of collaboration with the service user [10], research often reflects a discrepancy between rhetoric and actual practice favoring the medical model, as viewed by service users and reflected in occupational therapy clients' narratives $[3,6,7]$.

\subsection{Occupational therapy and disability studies}

The interdisciplinary field of Disability Studies, which emerged following other social action discourses such as gender studies, might serve to explain the aforementioned discrepancy in the OT field. Disability Studies promote a shift from emphasizing the prevention/treatment/remediation paradigm to an increasing recognition and incorporation of the social/cultural/political paradigm [8]. This view describes the social components of disability and demonstrates how social structures may oppress and discriminate against people with disabilities even when presented as client-centered [9]. At a declarative level, occupational therapy has formally adopted the social model of disability [3], and the incorporation of the client's perspectives and preferences into practice. Still, the majority of occupational therapy interventions are chiefly deficit-based, and may be less fitting to disability studies notions [10].

It seems that the pedagogy of occupational therapy faces new challenges fueled by the tensions between the social and medical model, as well as emerging notions from the field of disability studies [11]. Two of the major issues posed are regarding (a) the voice of people with disabilities in occupational therapy education and practice; and (b) the experiences of powerlessness and oppression as part of the occupational therapy intervention [11].

\section{Service user participation in occupational therapy education}

The slogan "nothing about us without us" or the more recently adopted "everything about us with us" represents the demand of people with disabilities to be involved in all decisions concerning their person and community [12]. It follows that educating professionals who are being prepared to provide services to people with disabilities falls under this category. The health and welfare literature stemming largely from the field of social work discusses various levels of service user involvement in the classroom, limited mostly to one-time guest lecturers recounting their personal experiences. In addition, service users are sometimes mentioned as taking part in the evaluation of students in fieldwork experiences, in admissions interviews, and as co-researchers. However, very few references have been made to service users as trainers or teachers [1, 13-16].

One alternative to involve more service users on a formal level in the classroom is through coteaching. Co-teaching (interchangeably referred to as team-teaching, collaborative teaching, and shared teaching) [17], has been reported in different learning contexts. Co-teaching can be defined as a pedagogy that involves two or more teachers planning, teaching, and assessing the same students [18]. While this term is often used in relation to sequential teaching, whereby different faculty members, often from different professional backgrounds, lecture sequentially throughout the course, here we explore a co-teaching approach hinging on a simultaneous teaching partnership between a faculty member and a service user.

Co-teaching has generally been positively accepted and viewed as a pedagogy that offers an opportunity for shared learning not only between teachers, but also between teachers and students [19]. Co-teachers can serve as role models for students as examples of authentic partnership; sharing power, decision making, and building a common knowledge base [18]. Below we present a co-teaching model which reflects the equal importance of professional knowledge, and knowledge that develops based on lived experience. The ongoing dialogue between these two knowledge bases leverages the development of new knowledge that sets the foundation for an authentic, collaborative client centered practice.

\subsection{Implementation of a co-teaching model}

A series of three consecutive requisite courses are taught in the first, second and third year of a Bachelor's of Occupation Therapy (BOT) program at a leading college in Israel. Each year the class meets four times a semester for 6-7 hours each time in a workshop setting. The number of students in the class varies between 40-55 students depending on the program's overall enrolment. Most of the students are female, aged 22-28. Several of the students have close family members with disabilities, and several others have learning difficulties.

The co-teachers (two of the authors) have been collaborating as disability rights advocates for ten years and have been co-teaching the courses which they developed since 2009. One of them, Shira, is a 
female faculty member with professional and academic experience in occupational therapy who is the head of the occupational therapy department at the college. She also serves as an advisor to the National Commissioner on Equal Rights for People with Disabilities at the Ministry of Justice. The other co-teacher, Yoav, is a male adjunct faculty member and service user with cerebral palsy who uses a wheelchair and also has severe learning difficulties. He holds a degree in education and sociology and worked for many years as the spokesperson for a leading disability activist organization. He is presently the head of the National Council for the Rehabilitation of People with Psychiatric Disabilities in the Ministry of Health.

The primary objective of the series of courses was to promote the development of students' critical thinking skills regarding their future practice within the community of people with disabilities. The learning framework enables the students to critically explore, over the three years of training, the role of occupational therapy in the field of disability as well as the potential opportunities inherent in partnership work with service users in practice.

Two teaching models were employed to further these aims. First, partnership work [20] is demonstrated through a dialogue that characterizes the co-teaching dyad and through intermittent partnerships with various stakeholders. The second model is that of critical pedagogy [21], which is utilized in the planning and development of the course, creating opportunities for critical thinking and authentic, reflective dialogue, as well as promoting partnership work between the co-teachers and the students. This paper is based on the assumption that together, these two models have the potential to create learning spaces where some of the power differentials can be challenged, thereby providing opportunities to integrate alternative dialogues into the students' developing professional identities.

\subsection{Course description}

The first course in the series typically takes place in the second semester of the students first academic year. The course content focuses on the study of personal accounts of disability, presented within a framework that is guided by the social model of disability. Students are exposed to the internal perspective of disability as perceived by service users and their family members, and address issues that people with disabilities may face in their lifetime.
The teaching takes a variety of forms, including formal lectures, small group sessions, one-time visits by service users and their family members. More creative techniques include a half day disability experience role play, films, and other projective activities designed to promote individual reflection, and class dialogue.

The second course is typically scheduled in the first semester of the students' second academic year. The course content further deepens student involvement in disability issues by introducing the notion of the disabled community as well as exploring various models of advocacy (e.g self-advocacy, organizational advocacy, professional advocacy etc.). In addition to the teaching techniques utilized in the first year course, students take part in a national activity designed to mark the International Day of People with Disabilities. This may include participating in a conference organized by the National Commissioner on Equal Rights for People with Disabilities, or a visit to Parliament on a day that all committee discussions are dedicated to disability related issues. This involvement enables the students to witness advocacy in action and serves as a trigger for further discussions, as well as class assignments and presentations.

The third course takes place in the second semester of the students' third academic year following two periods of field-work experience. The earlier class format continues but this course focuses on professional dilemmas and conflicts presented by groups of students and guest speakers. Students are encouraged to explore therapy in practice, and apply social models of disability to their fieldwork experience. Here, the learning process that has taken place over the series of courses is revisited by examining the critical dialogue that emerged around partnership and the respective roles of the occupational therapist and service user, as well as that of the students.

\section{Dilemmas faced and insights gained from the co-teaching experience}

\subsection{Dealing with power differentials}

At the beginning of the series of courses, our students were a bit perplexed by the co-teaching model and uncertain about Yoav's role in the dyad. Shira and Yoav represent seemingly very different roles; Shira not only holds academic credentials, but is also the head of the BOT program, 
and while Yoav has extensive lobbying skills as a disability activist, he is an external lecturer. Furthermore, Yoav has severe learning difficulties, and, while holding an undergraduate degree, he cannot read or write. When these differences were acknowledged at the outset of the course, the authors observed that while the students did not explicitly question the hierarchy being played out in front of them, their actions did initially represent recognizing Shira as the lead administrator and educator in the classroom. It seemed easier for the students to follow the familiar routine than meet the challenge of this new approach to learning.

\subsection{Dealing with power differentials: Authors' personal perspectives}

In order to tackle the aforementioned concerns, we, as the co-teachers had to re-evaluate our teaching methods in order to implement a paradigm that would serve to minimize the perceived power discrepancy while maximizing authentic dialogue and learning for all parties. Looking to identify the main features of co-teaching that embody authentic partnership, and examining our experiences, we drew on the facilitation of joint reflections and recognized the importance of equal power and shared responsibility and accountability between co-teachers [18]. As coteachers, we were mutually involved in all aspects of the teaching process: planning, delivery and evaluation. We developed the curriculum together and were both posted as co-teachers on all syllabus materials. We conducted every interaction together, including class attendance and student advising. However, answering electronic communication together was challenging; Shira read all correspondence as well as completed written assignments to Yoav (because of his learning difficulties). This soon became impractical as we were unable to meet a reasonable response rate to students. Following a transition period in which Shira would respond in the name of both, we developed a practice, explicit to students, by which Shira was responsible for all electronic communication, and consulted with Yoav regarding issues of critical value and eliciting his direct response when student questions were directed to him. All decisions regarding course content and assignments were made jointly. We were transparent about these activities and often we continued our open dialogue in class. As proved to us both intrinsically by our own sentiments and externally through students' feedback, the actions taken did indeed result in the acceptance of both co-teachers as equals serving complementary roles within the dyad. For example, while the students initially addressed Shira with their questions, as the course developed, they began to address Yoav more frequently, and would often seek out the experiential knowledge of Yoav.

\subsection{Dialogue as pedagogy}

The teaching and learning in these courses is grounded in reflective dialogue - dialogue between the two co-teachers, between the teachers and students, among the students themselves, and between the class and one-time lecturers. The nature of dialogic learning reduces the power differentials between teacher and learner and acknowledges the importance of ambiguity and disagreement as learning tools. In these courses we encouraged our students (and ourselves) to question formal knowledge through the lens of both the medical model and the social model and explore how they may both impact working with individuals with disabilities. Over time, we noticed that the students tend to clearly adopt the social model's perspective and yet at times it seemed contrived. Reflecting on our roles as co-teachers we became aware of the impact of our own dialogues in the classroom, both deeply grounded in the social model and thereby giving little room for other voices to emerge. While believing that we were modeling acceptance of different voices, we may in fact be stifling their legitimacy by imposing our own biases. Following this realization, we incorporated the medical model and the social model in more balanced proportion and tried to tone down our own statements, especially at the preliminary stages of the courses in the first academic year.

\subsection{Students' views on knowledge legitimacy}

As the students progressed through the series of courses, they seemed to have accepted the role of service users, and in particular, the vital role of the lived experience. As opposed to an earlier study which reported that social work students doubted the authenticity of the service user role [22], our second year occupational therapy students seem to have accepted its authenticity. In fact, we noticed that our students began doubting evidence not based on the lived experience - deeming it unworthy or irrelevant, thus seemingly replacing one 'truth' with another. This phenomenon led us to reevaluate our strategy by 
reflecting upon the basic components of the critical pedagogy which we applied. Socialization towards critical thinking requires that our students challenge their assumptions about the world, including disability, and recognize that there may be other options that need to be explored [23]. However, it seems that merely presenting new ideas and encouraging our students to doubt existing standards is not enough [23]. Rather, we need to actively support our students in critically absorbing these new ideas, and integrating them into their developing professional knowledge base.

\section{Conclusion}

One of the fundamental ideas of the social model of disability is the acknowledgement of the voices of people with disabilities regarding all aspects of their lives, and the need to recognize them as equals in working partnerships, especially in the fields of health and welfare. Therefore, a co-teaching pedagogy was chosen as the means for modeling partnership work and for including the voice of disabled people within the classroom setting. This framework was structured to integrate the social model of disability into occupational therapy education. We would like to suggest that by using a disability studies framework focusing on the multiple barriers facing individuals with disabilities, provides the students with a unique opportunity to explore and experience different viewpoints, broadening their professional perspectives and contributing to the development of their professional identities as collaborative occupational therapists. Over the years, since the implementation of this pedagogic model, recurrent feedback from our students highlights that the experience of learning with a disabled co-teacher "brings the message home loud and clear".

\section{Conflict of interest}

The authors have no conflict of interest to report.

\section{References}

[1] Gitlow L, Flecky K. Integrating disability studies concepts into occupational therapy education using service learning. American Journal of Occupational Therapy 2005;59(5):546-53.

[2] Hansen AM. Bridging theory and practice: Occupational justice and service learning. Work 2013;45(1):41-58.
[3] Kielhofner G. Rethinking disability and what to do about it: Disability studies and its implications for occupational therapy. American Journal of Occupational Therapy 2005;59(5):487-96.

[4] Reilly M. Occupational therapy can be one of the great ideas of 20th century medicine. The American Journal of Occupational Therapy: Official Publication of the American Occupational Therapy Association 1962;16:1.

[5] Yerxa EJ. Eleanor Clarke Slagle lecture. Authentic occupational therapy. The American Journal of Occupational Therapy: Official Publication of the American Occupational Therapy Association 1966;21(1):1-9.

[6] McCormack C, Collins B. Can disability studies contribute to client-centred occupational therapy practice? The British Journal of Occupational Therapy 2010;73(7):339-42.

[7] Palmadottir G. Client-therapist relationships: Experiences of occupational therapy clients in rehabilitation. British Journal of Occupational Therapy 2006;69(9):394-401.

[8] Davidson H, Evans S, Ganote C, Henrickson J, JacobsPriebe L, Jones DL, Prilleltensky I, Riemer M. Power and action in critical theory across disciplines: Implications for critical community psychology. American Journal of Community Psychology 2006;38(1-2):63-77.

[9] Oliver M. A sociology of disability or a disablist sociology. Disability and Society: Emerging Issues and Insights 1996:18-42.

[10] Hammell KW. Perspectives on disability \& rehabilitation: Contesting assumptions, challenging practice. Elsevier Health Sciences 2006.

[11] Whalley Hammell KR. Client-centred occupational therapy: The importance of critical perspectives. Scandinavian Journal of Occupational Therapy 2015;22(4):237-43.

[12] Hon T. Part One: Office for Disability Issues and government news. - Office for Disability Issues [Internet]. Odi.govt.nz. 2011 [cited 2014August 29]. Available from: http://www.odi.govt.nz/resources/publications/email-upda te/2011/2011-06-24-part-one.html

[13] Molyneux J, Irvine J. Service user and carer involvement in social work training: A long and winding road? Social Work Education 2004;23(3):293-308.

[14] Levin E. Involving service users and careers in social work education. London: SCIE; 2004.

[15] Block P, Ricafrente-Biazon M, Russo A, Chu KY, Sud S, Koerner L, Vittoria K, Landgrover A, Olowu T. Introducing disability studies to occupational therapy students. American Journal of Occupational Therapy 2005;59(5):554-60.

[16] Waterson J, Morris K. Training in 'social'work: Exploring issues of involving users in teaching on social work degree programmes. Social Work Education 2005;24(6):653-75.

[17] Crow J, Smith L. Co-teaching in higher education: Reflective conversation on shared experience as continued professional development for lecturers and health and social care students. Reflective Practice 2005;6(4):491-506.

[18] Gollan S, O'Leary PJ. Teaching culturally competent social work practice through black and white pedagogical partnerships. Social Work Education 2009;28(7):707-21.

[19] Riche P, Taylor I. The learning, teaching and assessment of partnership work in social work education - Guide home [Internet]. Scie.org.uk. 2008 [cited 2011 May 28]. Available from: http://www.scie.org.uk/publications/guides/guide23/ index.asp

[20] Maria Galheigo S. What needs to be done? Occupational therapy responsibilities and challenges regarding human rights. Australian Occupational Therapy Journal 2011;58(2):60-6. 
[21] Gutman C, Kraiem Y, Criden W, Yalon-Chamovitz S. Deconstructing hierarchies: A pedagogical model with service user co-teachers. Social Work Education 2012;31(2):202-14.

[22] Saleebey D, Scanlon E. Is a critical pedagogy for the profession of social work possible? Journal of Teaching in Social Work 2005;25(3-4):1-8.
[23] Lederer JM. Disposition toward critical thinking among occupational therapy students. American Journal of Occupational Therapy 2007;61(5):519-26. 